\title{
Mother's hand tool as a skin-to-skin contact simulation instrument decreases pain levels in newborns
}

\author{
Yesim Ceylantekin ${ }^{1}$, Nuriye Buyukkayaci Duman ${ }^{2 *}$, Dilek Ocalan ${ }^{3}$, Senay Topuz $^{4}$, \\ and Betul Yildiz Ucar ${ }^{5}$
}

\section{ABSTRACT}

\section{BACKGROUND}

Sensory stimulation activates the gate control mechanism, raises the level of beta endorphins, and the secretion of beta endorphins increases the pain threshold, reducing or eliminating the feeling of pain. It has been reported that skin-to-skin contact or sensual stimulation reduces stress, pain and crying time in newborns. The present study aimed to examine the effect of the mother's hand tool (MHT) - developed by the researchers for three purposes: touch, positioning and vibration - on pain levels in newborns.

\section{METHODS}

A quasi-experimental study was conducted involving 52 newborns aged 0-15 days who were being treated in the neonatal intensive care unit. The MHT was applied to support the newborn and was applied 8 times in 24 hours for 3 minutes in total. Demographic data collection form (DDCF), neonatal evaluation form (NEF) to assess the respiratory rate, pulse rate, $\mathrm{SPO}_{2}$ and $\mathrm{CO}_{2}$ level, and neonatal infant pain scale (NIPS) were used to collect data. The Wilcoxon signed rank test was applied to analyse the data. A p value of $<0.05$ was considered to be statistically significant.

\section{RESULTS}

After the MHT application, it was revealed that there was a significant difference in pulse rate $(\mathrm{p}=0.000), \mathrm{S}_{\mathrm{P}} \mathrm{O}_{2}$ level $(\mathrm{p}=0.029), \mathrm{CO}_{2}$ level $(\mathrm{p}=0.000)$ and NIPS pain scores (hour 6,9,12,15,18, and 24) and total NIPS ( $\mathrm{p}=0.000)$ pain scores, before and after MHT practice.

\section{CONCLUSION}

This study demonstrated that MHT application to the newborns had a decreasing effect on pain level, heart rate, $\mathrm{CO}_{2}$ level, and an increasing effect on $\mathrm{S}_{\mathrm{p}} \mathrm{O}_{2}$ level.

Keywords: Mother's hand tool, procedural pain levels, skin-to-skin contact simulation, newborns.
${ }^{1}$ Afyonkarahisar University of Health Sciences, Faculty of Health Sciences, Department of Nursing, Afyonkarahisar, Turkey ${ }^{2}$ Hitit University, Faculty of Health Sciences, Department of Nursing, Çorum, Turkey

${ }^{3}$ Tokat Gaziosmanpasa University Faculty of Health Sciences, Department of Nursing, Tokat, Turkey

${ }^{4}$ Ankara University, Faculty of Health Sciences, Department of Midwifery, Ankara, Turkey

${ }^{5}$ Konya Numune Hospital, Third Level Intensive Care Unit, Konya, Turkey

\section{Correspondence:}

*Nuriye Buyukkayaci Duman Hitit University, Faculty of Health Sciences, Department of Nursing, Corum, Turkey

Email :nurfatihh@hotmail.com ORCID ID : 0000-0002-4246-3607

Date of first submission, March 6, 2021

Date of final revised submission, May 24, 2021

Date of acceptance, June 2, 2021

This open access article is distributed under a Creative Commons AttributionNon Commercial-Share Alike 4.0 International License 


\section{INTRODUCTION}

A number of neonates, during the first days of life in the postpartum period, experience painful processes because of drug administrations, heel lancing, venipuncture/arterial puncture, venous interventions, neonatal evaluation and positioning. Behavioural or neurological problems may arise in infants if the pain is not treated effectively in this period. ${ }^{(1-3)}$ Healthcare professionals are responsible for reducing the pain that neonates experience and helping them to cope with it. The pain has two forms of treatment: pharmacological and non-pharmacological. ${ }^{(1-3)}$ Nonpharmacological methods are necessary to decrease analgesic drug use in the neonatal intensive care unit (NICU) and hospitalization period. In addition, healthcare professionals may prefer those methods since they are affordable and easily applicable. ${ }^{(4-6)}$ According to the literature, non-pharmacological methods which play a key role in pain management in neonates support them to cope with the pain and reduce the stress level. In addition, these methods are widely preferred since they are easily applicable and affordable. The methods reduce drug use and the risks of side effects as well. ${ }^{(6,7)}$

The distraction methods may be utilized by using the visual and auditory senses or sense of touch and taste in order to reduce the pain in newborns. ${ }^{(6,7)}$ As the distractive stimulant is removed, the pain becomes the main focus. ${ }^{(6,7)}$ Skin-to-skin contact (SSC) or kangaroo care (KC), massage, touching and embracing, crooning or avoiding loud talk close to the baby, allowing non-nutritive sucking, giving breast milk, breastfeeding, or giving oral sugared fluids are the distractive methods that reduce pain and stress. ${ }^{(8-10)}$ In addition, such non-pharmacological methods as holding, positioning, individualised care, provision of aromatic and maternal smells, mechanical vibration, acupuncture, and music have been used to control the pain. ${ }^{(8-10)}$

Touching and embracing are essential for the newborns with the purpose of maintaining SSC and reinforcing the trust sensation. ${ }^{(1)}$ Since preterm newborns are more hypotonic than fullterm newborns, they should be supported and in order to preserve flexion posture it is recommended that, if necessary, the infant should be swaddled for support. A towel, blanket or roll cloth can be used to maintain stabilisation. ${ }^{(11)}$ Similarly, it has been suggested that $\mathrm{KC}$ is important in pain management as well. Moreover, it has been reported that $\mathrm{KC}$ application decreases the pain score in infants and the duration of their crying during heel lancing. ${ }^{(12-14)}$

Studies on the subject have reported that SSC reduces the emotional stress and shortened crying times in the newborns, as well as improves parent-baby attachment and safe interaction. ${ }^{(12-}$ ${ }^{14)}$ In addition, the newborn calms down, the pulse rate decreases and the body temperature is regulated with the sensory stimulation. It has been reported that $\mathrm{SSC}$ has a decreasing effect on pain. When the literature is reviewed, there are studies reporting that SSC positively affects blood gas levels in newborns..$^{(12-14)}$

In addition, sensory stimulation activates the gate control mechanism, raises the level of beta endorphins, and the secretion of beta endorphins increases the pain threshold, reducing rather than eliminating the feeling of pain. ${ }^{(15)}$ When studies conducted with newborns on the subject are examined, it is seen that sensory stimulation techniques such as $\mathrm{SSC}, \mathrm{KC}$, vibration and massage reduce neonatal stress, resulting in a significant decrease in heart rate, blood pressure and pain scores. ${ }^{(16-18)}$

In the study of Herrington and Chiodo ${ }^{(16)}$ it was reported that the heart rate and crying time of babies who did not receive the gentle human touch (GHT) method as a simulation of SSC during heel lancing in newborns were higher than those in the group receiving GHT. In the study of McGinnis et al. ${ }^{(17)}$ it was reported that the newborns to whom vibration was applied during the heel lancing procedure had a more stable heart rate and pain scores were lower than had the group who did not receive vibration. In the systematic review study of Ueki et al. ${ }^{(18)}$ it was determined that mechanical vibration was 
effective in reducing pain from needle-related procedures (NRPs) in children. In the study of Dolu and Karakoc ${ }^{(19)}$ examining the effect of the mechanical vibration technique during heel lancing, the pain scores of the newborns in the intervention group in which mechanical vibration was applied were found to be lower than in the group without mechanical vibration. It was reported by Abdallah et al. ${ }^{(20)}$ that the pain scores of premature infants who received massage therapy were lower than those of infants who did not receive massage therapy.

When the studies on the subject are examined, it is seen that for practices such as reducing neonatal intensive care stress, kangaroo care to relieve pain, sensual contact, and vibration there is definite evidence of improved neurological and behavioural outcomes, although the evidence seems to be insufficient for other applications. ${ }^{(16-}$ ${ }^{18)}$ In these studies, it is seen that the relationship of a single technique to neonatal pain management is generally examined. ${ }^{(18-20)}$ In our study unlike other studies, the aim was to examine the effect of the mother's hand tool (MHT) - developed by the researchers for three purposes: touch, positioning and vibration- on pain levels in newborns.

\section{METHODS}

\section{Research design}

A quasi-experimental study was conducted at the Intensive Care Unit in Afyonkarahisar University of Health Sciences, Hospital of Medicine, Faculty of Health Sciences, between January and March 2018.

\section{Research subjects}

Fifty two newborns who were $0-15$ days old and who met the inclusion criteria of the study, having been treated in incubators for less than a month, were included in the study. The sample size was determined using $90 \%$ power to detect a mean of paired differences of 2.1 with a standard deviation of differences of 1.4 and a significance level (alpha) of 0.05 , resulting in 52 newborns aged 0-15 days.
Infants who were aged 0 and 15 days, born between 32 and 40 gestational weeks and whose parents agreed to participate and who met the criteria were included in the study. Excluded from the study were infants who had congenital anomalies, haemorrhages, contraindications towards position change, heart disease or severe respiratory distress, had undergone serious operation and infants who received morphine, fentanyl, muscle relaxants, dilantin or phenobarbital.

\section{Study instruments}

Three instruments were used to collect data. The first instrument was the demographic data collection form (DDCF) developed by researchers to assess the infant's gender, birth weight, height, weight, week of birth, delivery type, Apgar scores, sleeping position, breastfeeding status, vital signs and the reason for neonatal intensive care admission. The third instrument was the neonatal infant pain scale (NIPS) that was developed by Lawrence et al. ${ }^{(21)}$ to assess behavioural responses and physiologic pain responses of preterm and full-term newborns and was translated into Turkish by Akdovan and Yildirim ${ }^{(22)}$ and validated in 1999 by Akdovan. Lawrence et al. ${ }^{(21)}$ found the reliability coefficient of NIPS to be in the range of 0.92-0.97. In addition, Akdovan and Yyldyrym ${ }^{(22)}$ reported that the Cronbach's value is between 0.83 and 0.86 . The scale comprised of five behavioural indicators (facial expressions, cry, state of arousal, arms, legs) and one physiologic indicator (breathing pattern). With the exception of "cry," which had three possible score descriptors $(0,1$, or 2$)$, each behavioural indicator was scored with 0 or 1 . The total score ranged between 0 and 7 . Higher scores represented higher levels of pain. The NIPS is very easy and quick to use. The data for NIPS were collected by video recording. In this study, Cronbach's alpha of the scale was between 0.91 and 0.97 .

\section{Study procedure}

The newborns included in the study were supported in the incubator with a MHT instead 
of a towel or a rolled cloth. The position of the newborns was changed every 3 hours (prone, supine, right-lateral and left-lateral position) by the MHT. The application of MHT which included supporting the newborn and providing vibration, was performed 8 times in 24 hours for 3 minutes in total, including interventions. Heart rate, $\mathrm{S}_{\mathrm{P}} \mathrm{O}_{2}$ value, $\mathrm{CO}_{2}$ rate measurements were taken with a pulse oximeter device before and after the application of the MHT. In addition, the respiratory rate of newborns not connected to a mechanical ventilator was measured by the researcher by observing the rib cage movement. The respiratory rate of newborns connected to a mechanical ventilator was measured by means of a device. Measurement of the neonate's vital signs (axillary temperature, heart rate and respiratory rate) was done directly during direct skin to skin contact for 12 times (every 2 hours) to confirm their stability, then their mean values were recorded, and all other routine care was done. The measurement results obtained were recorded in the NEF. Also, the NIPS was applied before and after MHT application during the interventions.

\section{Mother's hand tool (MHT)}

The MHT is a hand-like tool, made of rubber and bar of silicone, which vibrates the newborns. Non-allergenic components were used in view of the newborn's skin sensitivity. Therefore, more effective results were expected by integrating touching, proper positioning and mechanical vibration techniques without harming the newborn's skin. It was particularly designed to be like a mother's hand to induce the feeling that mother is touching. The MHT was developed by us and was given its name because it resembles the hand of the mother (Figure 1). The MHT is considered to be important in creating a sense of trust in the infant who is separated from the mother, since it resembles the mother's hand, unlike the rolled towel currently used in the clinic (Figure 2). The functions of the MHT of touching, proper positioning, and mechanical vibration have been integrated with the aim of pain control in newborns.

\section{Ethical consent}

This study has been ethically approved on 11/12/2017 by Afyonkarahisar Kocatepe University Faculty of Medicine under No. 2017/ 279. Written and oral consent of the respondents' parents were obtained as well to allow the investigators to evaluate the pain status of the newborns.

\section{Statistical analysis}

The data were evaluated using the IBM SPSS 22.0 package program (IBM Corp., Armonk, NY, USA). Number, percentage, mean, and standard deviation were used in the evaluation of descriptive data. The Shapiro-Wilk normality test was performed to determine whether the data were normally distributed. In the analysis, it was found that the distribution was

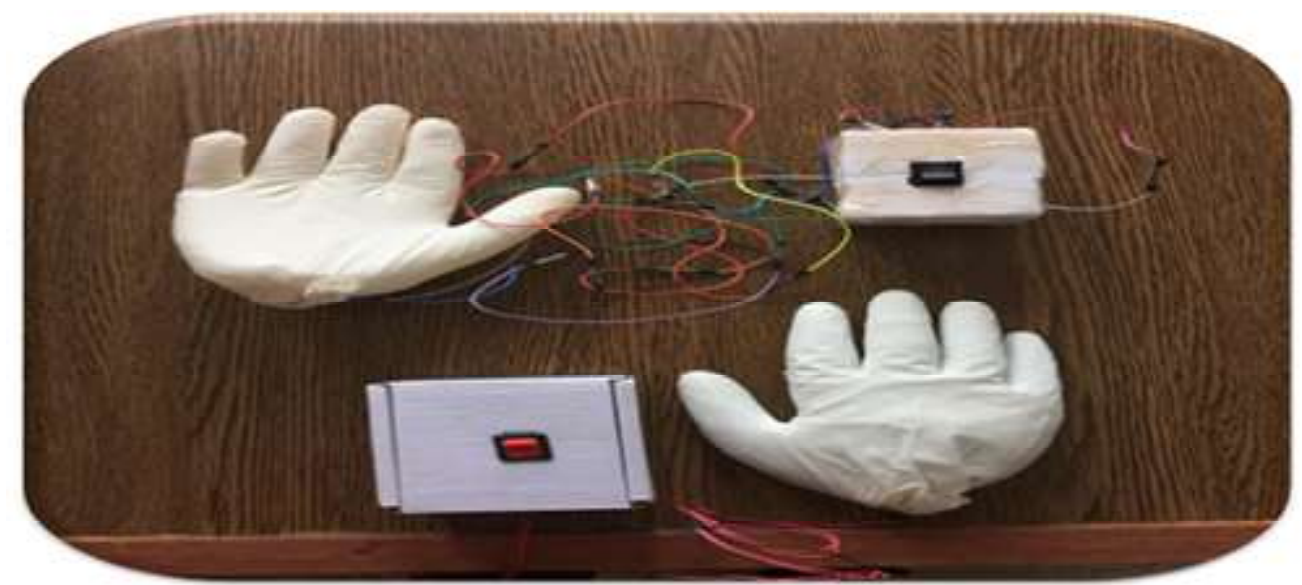

Figure 1. The maternal mechanism used to position the babies in intensive care 


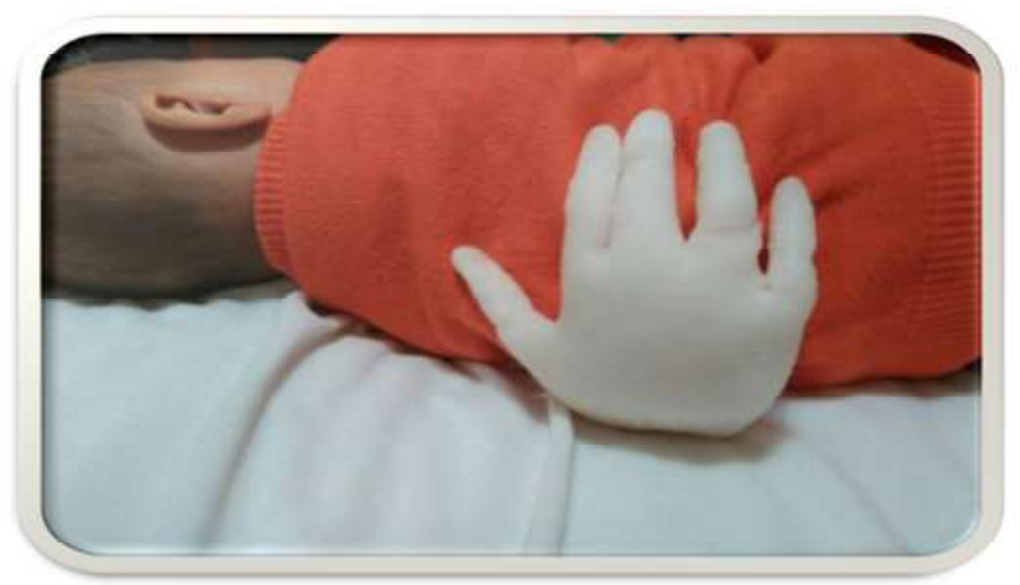

Figure 2. The use of mother's hand tool as a representative in positioning

not normal. The Wilcoxon signed rank test was used to compare two groups of non-parametric data. A p-value of $<0.05$ was considered to be statistically significant.

\section{RESULTS}

A total of 52 newborns participated in this study and were followed up for 24 hours (Figure $3)$.

In this study, the median gestation week of the newborns was 35.3 (29-40) weeks, the mean age was $3.4(0-15)$ days, and $55.8 \%$ of the newborns were girls. The median birth weight of the newborns was $2150(1100-4000) \mathrm{g}$, while the median height was $43(41-46) \mathrm{cm}$, and $63.5 \%$ of the newborns were delivered by Caesarean section. The reasons for admission to the NICU were hyperbilirubinaemia $(63.5 \%)$, hypoxia (25.0\%), premature $(25.0 \%)$, and low birth weight (15.4\%). In addition, $96.2 \%$ of the newborns received breast milk and all of them slept in the supine position. When the distribution of vital signs of newborns was examined, the median axillary temperature was $36.2^{\circ}(35-37)$, the median heart rate was 141 (130-160) $\mathrm{x} / \mathrm{min}$, , and the median respiratory rate was $48(46-56) \mathrm{x} / \mathrm{min}$. While the median oxygen saturation was 95.5 (94-99) \% , and the median carbon dioxide saturation was 36 (35-43) \% (Table 1).

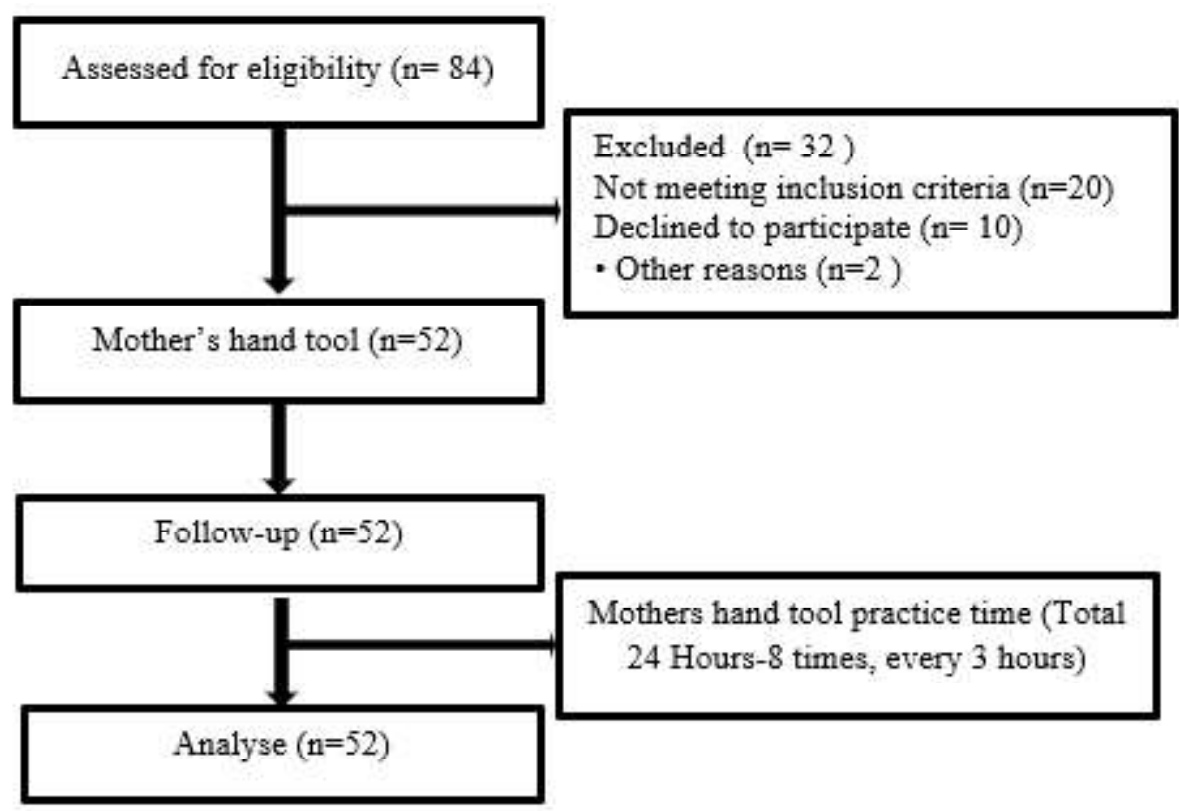

Figure 3. Flowchart of the participants 
Table 1. Characteristics of the subjects at base-line $(n=52)$

\begin{tabular}{|c|c|}
\hline Characteristics & n (\%) \\
\hline Gestational age (weeks) * & $35.3(29-40)$ \\
\hline \multicolumn{2}{|l|}{ Age (days)* } \\
\hline Gender & $3.4(0-15)$ \\
\hline Male & $23(44.2)$ \\
\hline Female & $29(55.8)$ \\
\hline Birth weight $(\mathrm{g})^{*}$ & $2150(1100-40000)$ \\
\hline Height $(\mathrm{cm})^{*}$ & $43(41-46)$ \\
\hline \multicolumn{2}{|l|}{ Delivery type } \\
\hline Vaginal birth & $19(36.5)$ \\
\hline Caesarean section & $33(63.5)$ \\
\hline \multicolumn{2}{|l|}{ Apgar scores } \\
\hline 4- 6 & $27(52.7)$ \\
\hline $7-9$ & $25(47.3)$ \\
\hline \multicolumn{2}{|l|}{ Reason for NICU admission } \\
\hline Hyperbilirubinaemia & (34.6) \\
\hline Hypoxia & (25.0) \\
\hline Prematurity & $(25.0)$ \\
\hline Low birth weight & (15.4) \\
\hline \multicolumn{2}{|l|}{ Breastfeeding status } \\
\hline Taking & $50(96.2)$ \\
\hline Not taking & $2(3.8)$ \\
\hline \multicolumn{2}{|l|}{ Sleeping position } \\
\hline Supine & $52(100.0)$ \\
\hline \multicolumn{2}{|l|}{ Vital signs * } \\
\hline Axillary temperature $\left({ }^{\circ} \mathrm{C}\right)$ & $36.2(35-37)$ \\
\hline Heart rate $(\mathrm{x} / \mathrm{min})$ & $141(130-160)$ \\
\hline Respiratory rate $(\mathrm{x} / \mathrm{min})$ & $48(46-56)$ \\
\hline $\mathrm{SpO}_{2}$ saturation $(\%)$ & $95.5(94-99)$ \\
\hline $\mathrm{CO}_{2}$ saturation $(\%)$ & $36(35-43)$ \\
\hline \multicolumn{2}{|l|}{ Having diagnosed infection status } \\
\hline Yes & $0(0.0)$ \\
\hline No & $52(100.0)$ \\
\hline Skin contact treatment in incubator & 8 times and over in 24 - hour \\
\hline
\end{tabular}

*Data presented as Median (Min-Max)

A Wilcoxon signed rank test showed that there was a significant difference on weight gain on hour $9(\mathrm{p}=0.000)$, hour $12(\mathrm{p}=0.000)$, hour 15 $(\mathrm{p}=0.000)$, hour $18(\mathrm{p}=0.000)$, hour $21(\mathrm{p}=0.000)$ and hour $24(\mathrm{p}=0.000)$ between infants before the MHT practice group and those after the MHT practice group. The median $\mathrm{CO}_{2}$ level and heart rate significantly decreased in the post MHT practice group compared to the before MHT practice group. And the median $\mathrm{SpO}_{2}$ level increased after the MHT practice (Table 2).

\section{DISCUSSION}

In our study, it was determined that the MHT application performed during invasive procedures has a significant decreasing effect on the median NIPS scores of the newborns (at $6,9,12,15,18,24$ hours) and the median total 24-hour NIPS score. In other words, it can be said that MHT application reduces procedural pain in newborns. 
Table 2. Comparison of NIPS scores, total NIPS score, vital signs in newborns before and after MHT practice

\begin{tabular}{|c|c|c|c|}
\hline & $\begin{array}{c}\text { Before MHT Practice } \\
(\mathrm{n}=52)\end{array}$ & $\begin{array}{c}\text { After MHT Practice } \\
(\mathrm{n}=52)\end{array}$ & p value \\
\hline NIPS scores & Median & Median & \\
\hline \multicolumn{4}{|l|}{ Time of day (hour) } \\
\hline 3:00 & 0.06 & 0.05 & 0.729 \\
\hline 6:00 & 0.26 & 0.16 & $0.285^{*}$ \\
\hline 9:00 & 1.75 & 0.85 & 0.000 \\
\hline $12: 00$ & 3.50 & 0.00 & $0.000 *$ \\
\hline $15: 00$ & 4.40 & 0.00 & $0.000 *$ \\
\hline 18.00 & 2.80 & 1.10 & $0.000^{*}$ \\
\hline $21: 00$ & 1.50 & 1.24 & $0.000 *$ \\
\hline 24:00 & 0.32 & 0.25 & $0.000 *$ \\
\hline NIPS total scores & 3.40 & 0.22 & $0.000 *$ \\
\hline $\mathrm{SpO}_{2}$ saturation (\%) & 95.5 & 97 & $0.029 *$ \\
\hline $\mathrm{CO}_{2}$ saturation $(\%)$ & 36 & 31 & $0.029 *$ \\
\hline Axillary temperature $\left({ }^{\circ} \mathrm{C}\right)$ & 36.2 & 36.3 & 0.652 \\
\hline Heart rate $(\mathrm{x} / \mathrm{min})$ & 141 & 139 & $0.000^{*}$ \\
\hline Respiration rate $(\mathrm{x} / \mathrm{min})$ & 48 & 48 & 0.445 \\
\hline
\end{tabular}

Abbreviation NIPS, neonatal infant pain scale

According to the literature, it is reported that non-pharmacological methods such as skin contact, vibration, massage, and positioning are effective in relieving procedural pain in newborns. ${ }^{(1-3)}$ Similarly, in our study, it was determined that the application of the MHT which has three functions, skin contact simulation, vibration and positioning, reduces procedural pain in newborns.

In our study, after the MHT practice, the median $\mathrm{S}_{\mathrm{p}} \mathrm{O}_{2}$ increased and the median $\mathrm{CO}_{2}$ decreased in the newborns. In addition, after the MHT application, mean heart rate decreased. Studies on the subject show that pain in the newborn increases heart rate, causes ECG changes and negatively affects oxygenation. ${ }^{(16-}$ ${ }^{18)}$ On the other hand, with the reduction of pain in the newborn and the elimination of the stress factor of pain, heart rate slows down, oxygenation increases, and carbon dioxide saturation decreases. ${ }^{(16-18)}$ In this context, it can be said that the findings obtained in our study regarding the change in pain scores, vital signs and blood gas values before and after MHT application are compatible with the literature.

When the literature is reviewed, similar to our study it has been reported that skin-to-skin contact or similar sensual stimulation, vibration and positioning had a decreasing effect on stress, pain and crying time in newborns. ${ }^{(16-18)}$ It has been reported that some of the non-pharmacological studies have found a significant effect on pulse rate, respiration and oxygen saturation, and a decrease in motor activity and arousal states following invasive measures. ${ }^{(16-18)}$

Similar to the result of our study, Herrington and Chiodo ${ }^{(16)}$ investigated the gentle human touch (GHT) method during heel lancing in neonates. It has been revealed that infants who did not receive GHT had increased heart rate and increased duration of crying during the heel stick. Also infants who received GHT did not have decreased respiration and elevated heart rate. Also, Cadlayan and Balcy ${ }^{(23)}$ studied the duration of crying and pain scores in preterm neonates both in the usual positions and facilitated tucking during heel lancing. It has been determined that the pain scores of the neonates in facilitated tucking are relatively low and the duration of their crying is shorter as well. Chidambaram et al. ${ }^{(24)}$ using a crossover study on the effect of kangaroo care (skin-to-skin contact) in reducing heel lancing pain in preterm infants, found that kangaroo care was effective in reducing pain in 
preterm infants. Similarly, in the study of Sen and Manav, ${ }^{(25)}$ it was reported that kangaroo care was more effective than oral sucrose in relieving procedural pain in premature babies. In the study of Karimi et al., (26) it was determined that massage and kangaroo care had a pain-reducing effect in premature infants.In the randomized controlled trial by McGinnis et al. ${ }^{(17)}$ it was found out that the neonates in the vibration group had significantly lower pain scores and more stable pulse rates during heel stick and 2 minutes following heel lancing compared to those in the non-vibration group. Also, Dolu and Karakoc's ${ }^{(19)}$ study in which the effect of the mechanical vibration technique during heel stick in order to reduce the pain was observed, mean NIPS scores in the experimental group during and after the practice was lower than in the control group without the vibration technique. These findings are similar to those of our study.

The clinical implication of this study according to the results showed that at least 9 hours of MHT was effective in improving pain, heart rate, and $\mathrm{S}_{\mathrm{p}} \mathrm{O}_{2}$ and $\mathrm{CO}_{2}$ levels in the newborn. Therefore, mothers need to be encouraged and supported to provide MHT practice in NICUs. The limitation of our study was the quasi-experimental design used, which is useful when randomization is not possible. In this study, we chose to use a quasi-experimental design because of the ethical implications of randomising infants to receive or not receive the MHT practice. Future research using a true experimental design would be more rigorous and assist in controlling confounding variables.

\section{CONCLUSIONS}

As a result, it was demonstrated that MHT practice had a decreasing effect on pain levels, heart rates, and $\mathrm{CO}_{2}$ rates, and an increasing effect on $\mathrm{SPO}_{2}$ values in the newborns. The MHT practice is a safe and effective method of pain management in newborn.

\section{CONFLICT OF INTEREST}

No potential conflict of interest was reported by the author(s).

\section{ACKNOWLEDGMENTS}

We would like to thank the participating newborns who took part in this study. We also thank both parents of each of the newborns for their consent.

\section{CONTRIBUTORS}

YC, DO, NBD designed this study. YC, BY, NBD carried out the data analyses and reported the initial findings. NBD, ST contributed to the manuscript prepation and submission. All authors have read and approved the final manuscript.

\section{REFERENCES}

1. Boles J. Non-pharmacological strategies for addressing infant pain. Pediatr Nurs 2017;43:98100.

2. Erodlu A, Arslan S. Perception, evaluation and management of pain in the newborn. Duzce University J Inst Health Sci 2018;8:52-60.

3. Polkki T, Korhonen A, Laukkale H. Nurses' perceptions of pain assessment and management practices in neonates: a cross-sectional survey. Scand J Caring Sci 2018;32:725-33. doi: 10.1111/ scs.12503.

4. Field T. Preterm newborn pain research review. Infant Behav Dev 2017;49:141-50. doi: 10.1016/j.infbeh.2017.09.002.

5. Efe E, Dikmen S, Altas N, Boneval C. Turkish pediatric surgical nurses' knowledge and attitudes regarding pain assessment and nonpharmacological and environmental methods in newborns' pain relief. Pain Manag Nurs 2013;14:343-50. doi: 10.1016/j.pmn.2011.08.003.

6. Bucsea O, Riddell RP. Non-pharmacological pain management in the neonatal intensive care unit: managing neonatal pain without drugs. Semin Fetal Neonatal Med 2019;24:101017. doi: 10.1016/ j.siny.2019.05.009.

7. Williams N, Mac Lean K, Guan L, Collet JP, Holsti L. Pilot testing a robot for reducing pain in hospitalized preterm infants. OTJR Occup 
Participation Health 2019;39:108-15. https:// doi.org/10.1177/1539449218825436.

8. Akcan E, Yiðit R. Related approaches to pain management of neonatal nurses and physicians in the neonatal clinic in Turkey. ACU Health Sci J 2016;3:147-53.

9. De Clifford-Faugere G, Aita M, Le May S. Nurses' practices regarding procedural pain management of preterm infants. Appl Nurs Res 2019;45:52-4. https://doi.org/10.1016/j.apnr.2018.11.007.

10. Yavuz DE,Alpar PE. Interventional pain and nonpharmacological management in newborns and infants. Zeynep Kamil Med Bull 2018;49:169-78.

11. Rivas-Fernandez M, Roque I Figuls M, DiezIzquierdo A, Escribano J, Balaguer A. Infant position in neonates receiving mechanical ventilation. Cochrane Database Syst Rev 2016;11: CD003668. doi:10.1002/14651858.CD003668.pub4

12. Campbell-Yeo M, Johnston CC, Benoit B, et al. Sustained efficacy of kangaroo care for repeated painful procedures over neonatal intensive care unit hospitalization: a single-blind randomized controlled trial. Pain 2019;160:2580-8. doi: 10.1097/ j.pain.0000000000001646.

13. Pagni AM, Kellar S, Rood M. Effects of Kangaroo care on procedural pain in preterm infants: a systematic review. Honors Research Projects 2017;441. http://ideaexchange.uakron.edu/ honors research projects $/ 441$.

14. Benoit B, Campbell-Yeo M, Johnston C, Latimer M, Caddell K, Orr T. Staff nurse utilization of Kangaroo Care as an intervention for procedural pain in preterm infants. Adv Neonatal Care 2016; 16:229-38. doi: 10.1097/ANC.0000000000000262.

15. Zampino C, Ficacci R, Checcacci M, Catacuzzeno L. Pain control by proprioceptive and exteroceptive stimulation at the trigeminal level. Front Physiol 2018;9:1037. doi:10.3389/fphys. 2018.01037.

16. Herrington CJ, Chiodo LM. Human touch effectively and safely reduces pain in the newborn intensive care unit. Pain Manag Nurs 2014;15:10715. doi: 10.1016/j.pmn.2012.06.007.
17. McGinnis K, Murray E, Cherven B, McCracken $\mathrm{C}$, Travers $\mathrm{C}$. Effect of vibration on pain response to heel lance: a pilot randomized controltrial. Adv Neonatal Care 2016;16:439-48. doi: 10.1097/ANC. 0000000000000315.

18. Ueki S, Yamagami Y, Makimoto K. Effectiveness of vibratory stimulation on needle-related procedural pain in children: a systematic review. JBI Database System Rev Implement Rep 2019; 17:1428-63. doi: 10.11124/JBISRIR-2017-003890.

19. Dolu Kaya FN, Karakoc A. Efficacy of mechanical vibration of heel stick pain in neonates. Clin Exp Health Sci 2018;8:122-7.

20. Abdallah B, Badr LK, Hawwari M. The efficacy of massage on short and long term outcomes in preterm infants. Infant Behav Dev 2013;36:662-9. https://doi.org/10.1016/j.infbeh.2013.06.009.

21. Lawrence J, Alcock D, McGrath P, Kay J, MacMurray SB, Dulberg C. The development of a tool to assess neonatal pain. Neonatal Netw 1993;12:59-66.

22. Akdovan T, Yyldyrym Z. Assessment of pain in healthy neonates, investigation of the effects of pacifying and holding in arms. J Perinatal Med 2001;29:43.

23. Çaðlayan N, Balcy S. An effective pain reduction in preterm newborns method: fetal position. Florence Nightingale J Nurs 2014;22:63-8.

24. Chidambaram AG, Manjula S, Adhisivam B, Bhat BV. Effect of kangaroo mothercare in reducing pain due to heel prick among preterm neonates: a cross-over trial. J Matern Fetal Neonatal Med 2014;27:488-90. doi: 10.3109/14767058.2013. 818974.

25. Sen E, Manav G. Effect of Kangaroo care and oral sucrose on pain in premature infants: a randomized controlled trial. Pain Manag Nurs 2020;21:556-64. doi: 10.1016/j.pmn.2020.05.003.

26. Karimi F, Abolhassani M, Ghasempour Z, Gholami A, Rabiee N. Comparing the effect of kangaroo mother care and massage on preterm infant pain score, stress, anxiety, depression, and stress coping strategies of their mothers. Int J Pediatr 2020. doi:10.22038/IJP.2020.50006.3990. 